\title{
BUCCAL BONE GRAFT WITH SURGICALLY ASSISTED RAPID MAXILLARY EXPANSION IN YOUNG ADULTS; A CONE BEAM COMPUTERIZED TOMOGRAPHIC COMPARATIVE STUDY
}

\author{
Abdullah M Agniah*, Ashraf A El-Bedwehi ${ }^{* *}$, Hussein N Al-khalifa ${ }^{* * *}$, Wael A Al-Mohandes ${ }^{* * * *}$
}

\section{ABSTRACT}

Objectives: The aim of this study was to evaluate the dentoskeletal effect of buccal bone graft with buccal surgically assisted rapid maxillary expansion in young adults using cone beam computed tomography. Methods: The current randomized clinical study was conducted on a total sample of 21 orthodontic patients. The sample with mean age 20 Y. CBCTs were taken before and after orthodontic expansion. The patients were divided in to three groups, group I: consisted 7 patients treated with Hyrax expander, in conjunction with selected Buccopalatal corticotomy, group II: consisted 7 patients treated with Hyrax expander, in conjunction with selected Buccal corticotomy only, group III consisted 7 patients treated with Hyrax expander, in conjunction with selected Buccal corticotomy only, followed by immediately placement of bone graft directly over the decorticated plate. Results: The results showed high significant increase in buccal bone thickness in the group III. On the other hand, there was a significant decrease increase in buccal bone thickness in groups I\&II. Conclusion: The buccal bone graft with surgically assisted RME in young adult leads to increase in buccal bone thickness than the other technique without bone graft. The other two techniques without bone graft showed significant reduction in buccal bone thickness.

\section{INTRODUCTION}

Maxillary transverse deficiency (MTD) is one of the most pervasive and common skeletal problems in the craniofacial region, often combined with a simultaneous vertical or antero-posterior skeletal discrepancy $^{(1)}$. The most frequently reported clinical manifestations are uni- or bilateral posterior crossbite, palatal inclination of teeth, dental crowding, high palatal arch, narrow, tapering arch form and problems associated with nasal breathing ${ }^{(2)}$. Several studies have shown that the prevalence of posterior crossbite is between $2 \%$ and $16 \%{ }^{(3)}$.

In most cases, the discrepancy between maxillary and mandibular arch widths is due to insufficient maxillary arch width. Therefore, expanding maxillary arch width is a major goal of posterior crossbite treatment ${ }^{(4)}$. Numerous treatment modalities, including rapid palatal expansion with jackscrew, removable appliances, lingual W-arches, and quad-helix appliances have been recommended to correct maxillary arch constriction either by orthodontic and / or effect ${ }^{(5-8)}$.

Expansion, particularly in young patients ${ }^{(9)}$. Orthodontic effects include tooth tipping or bodily movement of the maxillary posterior teeth and canines. The most movement occurs during orthodontic expansion is tipping movement ${ }^{(10)}$.

\footnotetext{
${ }^{*}$ MCs Candidate, Dentist, Ministry of Health- Baniwalied- Libya

** Professor, Department of Orthodontics, Faculty of Dental Medicine (Boys) and Vice president for graduate studies and research, Al-Azhar University, Cairo, Egypt.

**** Lecturers, Department of Orthodontics, Faculty of Dental Medicine (Boys), Al-Azhar University, Cairo, Egypt.

**** Assistants professor and head, Department of Oral and Maxillofacial Surgery, Faculty of Dental Medicine (Boys), Al-Azhar University, Cairo, Egypt
} 
A more recent surgical orthodontic therapy was introduced by Wilcko et al., which included the innovative strategy of combining surgical corticotomy with alveolar grafting ${ }^{(11)}$. This technique referred to as Accelerated Osteogenic Orthodontics (AOO) and more recently to as Periodontally Accelerated Osteogenic Orthodontics (PAOO), this technique advocated for comprehensive fixed orthodontic appliances in conjunction with full thickness flaps and labial and lingual corticotomy around teeth to be moved. Alveolar augmentation of labial cortical plate were used in an effort to enhance and strengthen the periodontium ${ }^{(12,13)}$.

The increasing number of adult patients who seeking orthodontic treatment. Invite a different and challenging as well as necessitate special concepts and procedures, such as the use of invisible appliances, shorter periods of treatment, the use of lighter forces and more precise tooth movements ${ }^{(14)}$.The development of corticotomyassisted orthodontic treatment (CAOT) opened doors and offered solutions to many limitations in the orthodontic treatment of adults. This method claims to have several expansion, particularly in young patients ${ }^{(10)}$. Orthodontic effects include advantages, include a reduced treatment time, enhanced expansion, differential tooth movement, increased traction of impacted teeth and, finally, more post-orthodontic stability ${ }^{(14)}$. Using modern bone grafting techniques in an effort to enhance and strengthen the periodontium, ensures root coverage as the dental arch expanded ${ }^{(12,13)}$.

\section{MATERIAL AND METHODS}

The current randomized clinical study was conducted on a total sample of 21orthodontic patients randomly selected from a large pool of patients who were seeking treatment at out-patient clinic, Orthodontic Department, Faculty of Dental Medicine (boys), AL-Azhar University; Cairo. Sample size calculation was based on a power statistical analysis as follows: For an alpha error of 0.05 and power of $95 \%$, the minimum sample size required was estimated to be 21 patients, 7 patients in each arm.

The patients were randomly divided into three equal groups ( 7 patients each) according to the type of the corticotomy. Group I: included 7 patients treated with expansion with buccopalatal corticotomy. Group II: included 7 patients treated with expansion with buccal corticotomy only. Group III: included 7 patients treated with expansion with buccal corticotomy followed by immediately placement of bone graft directly over the decorticated plate. The process of randomization and group allocation was undertaken via a computerized simple online generated randomization plan. Using online software using online software found at the web site: http://www.graphpad.com/quickcalcs/randomize.

CBCTs were taken after achieving the study objectives to be used for analyzing the study measurements and comparison with the pretreatment CBCT data. Study casts, intraoral and extra-oral photographs were also taken after expansion has completed to be presented in the results section.

In all groups the expansion will be started after two weeks of surgical procedure. Activation of the appliance was initiated with one complete turn of the screw on the day after appliance insertion, thereafter, one quarter of a turn twice per day for each patient (one quarter turn of the expansion screw mechanism amounting to approximately 0.25 $\mathrm{mm}$ ) resulting in $0.5 \mathrm{~mm}$ per day expansion. The expansion continued for a period of (16-20 days). (Fig.1 \&Fig.2)

The CBCT images were acquired using a Planmeca Promax Mid machine. The machine was operating at the following protocol for all the scans of the study. Tube voltage $90 \mathrm{Kvp}$, Exposure time12 S, Current $12 \mathrm{~mA}$, Voxel size $200 \mathrm{~mm}$, Field of view $401 \mathrm{~cm}$ Height $\mathrm{x} 401 \mathrm{~cm}$ width $\mathrm{x} 401$ depth. After acquisition, data were exported and transferred in DICOM format and downloaded via a Compact Disk (CD) to a personal computer for linear software was utilized. 
Superimposition module was used to superimpose the postoperative scan over the preoperative. Orientation of the whole volume was made to ensure that the orthogonal reference lines (axial, coronal and sagittal) were following certain planes. Axial reference line was viewed at the sagittal plane and it was made passing through ANS and PNS, this orientation controlled volume anteroposterior orientation. At the axial view, two lines were present; sagittal and coronal reference lines. In order to assign maxillary plane, three points were identified at the level of the hard palate; ANS anteriorly, right and left posterior maxillary points (rPMP and 1PMP) ${ }^{(15,16)}$.

\section{Measurements: 172,187}

First the preoperative scan was highlighted, and at the coronal view, the measurement of maxillary base and alveolar width was measured at the level of upper first molar. Maxillary base width was measured as the horizontal distance between two points representing the first change of maxillary bone from vertical to horizontal orientation. Alveolar bone width was measured at different levels, as the distance between the maximum alveolar thickness, at crestal level and at the level of the mesio-buccal root apex. Molar inclination was measured as the angle between the line passing through mesio-buccal cusp tip and mesio-buccal root tip and another line parallel to the midsagittal plane. Alveolar thickness was measured at axial view where, $5 \mathrm{~mm}$ line was drawn at the same coronal view from the CEJ of upper first molar upwards, and then the axial line was moved to that level, where alveolar thickness buccal and palatal to mesio-buccal root was measured at that level (Fig. 1\&2) ${ }^{(17-19)}$.

After taking these measurements, preoperative scan was hidden and the post-operative scan was highlighted and the same measurements were taken according the same reference lines (Reference lines were irrelevant to anatomical changes between pre and post scans).

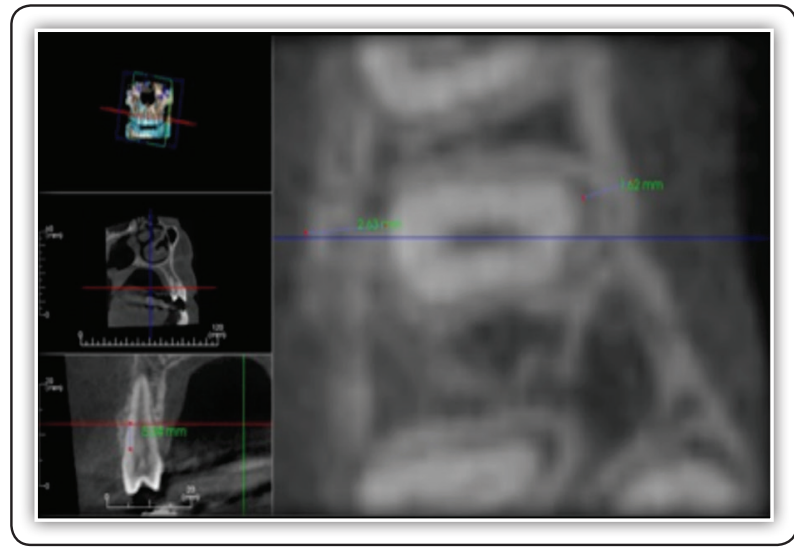

FIG (1) Measurements of maxillary first premolar bone thickness on the axial section.

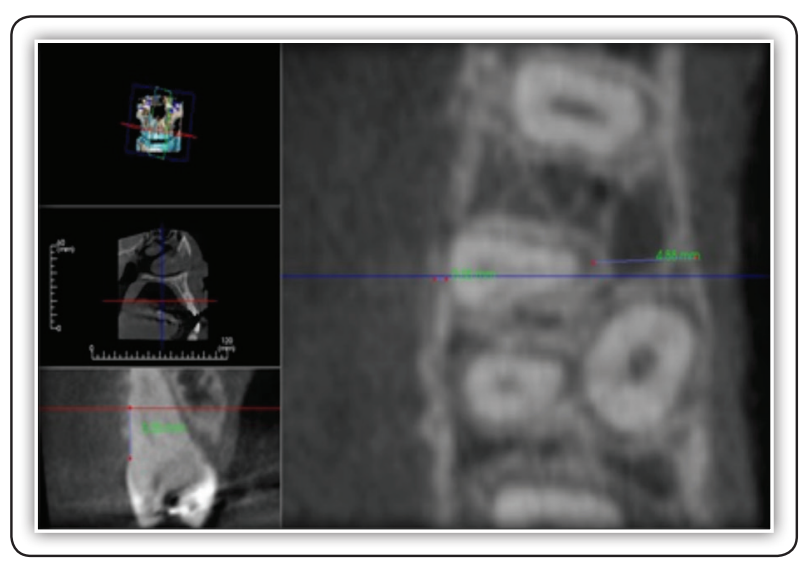

FIG (2) Measurements of maxillary first molar bone thickness on the axial section.

\section{Statistical analysis}

Descriptive statistics were calculated for each measurement. All statistical analyses were performed using the IBM ${ }^{\circledR}$ Statistical Package for Social Science (SPSS) Version 23 for Windows. Treatment changes between the 2 groups and between $\mathrm{T} 1$ and $\mathrm{T} 2$ were analysed with independent sample t-test. A value of $p<0.05$ was considered significant.

\section{RESULTS}

For analysis of distribution of data in the present study, Kolmogorov-Smirnov and Shapiro-Wilk tests were used, distribution of data, before and after expansion, that revealed normal distribution of the data so, parametric tests were used. 
To determine the intra-examiner error of measurements, paired sample t-test was conducted for the mean difference between the first measurements (data of the total sample) and the $2^{\text {nd }}$ measurements (data of $30 \%$ of the sample), demonstrates no statistically significant difference between $1^{\text {st }}$ and $2^{\text {nd }}$ measurements $(p>0.05)$.
Independent sample t-tests were used to determine the level of significance between the pre alignment and post alignment measurements within each group. Comparison among three groups was performed via One Way Analysis of Variance (ANOVA) and Bonferroni multiple range tests. $P$ value for all statistical tests was set at $p \leq 0.05$.

TABLE: Descriptive statistics and ANOVA for the treatment effect on linear and angular measurements among three groups.

\begin{tabular}{|c|c|c|c|c|c|c|c|c|c|c|c|}
\hline \multirow[b]{2}{*}{ Variable } & \multicolumn{3}{|c|}{ Group I } & \multicolumn{3}{|c|}{ Group II } & \multicolumn{3}{|c|}{ Group III } & \multicolumn{2}{|c|}{ ANOVA test } \\
\hline & 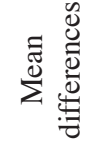 & SD & SE & 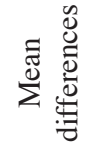 & SD & SE & 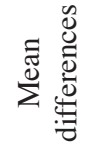 & SD & SE & $\mathrm{F}$ value & $\mathrm{P}$ value \\
\hline Max-width & 1.97 & 1.96 & 0.80 & 0.35 & 2.38 & 0.97 & 0.62 & 2.06 & 0.84 & 2.100 & $0.157 \mathrm{NS}$ \\
\hline Alv-width & 2.38 & 3.40 & 1.12 & 2.72 & 3.30 & 1.42 & 3.23 & 3.30 & 1.37 & 0.282 & $0.759 \mathrm{NS}$ \\
\hline RFP-tip & 3.55 & 1.06 & 0.84 & 3.55 & 1.38 & 0.38 & 3.53 & 2.89 & 1.18 & 1.157 & $0.341 \mathrm{NS}$ \\
\hline RFP-apex & 0.59 & 1.42 & 0.57 & 0.22 & 2.42 & 0.99 & 0.56 & 2.28 & 0.93 & 0.478 & $0.118 \mathrm{NS}$ \\
\hline RFP-angle & 4.98 & 3.79 & 1.14 & 4.94 & 3.88 & 1.85 & 4.89 & 2.93 & 1.99 & 0.501 & $0.222 \mathrm{NS}$ \\
\hline RFP-buccal & $0.25^{\mathrm{b}}$ & 0.43 & 0.19 & $0.46^{\mathrm{b}}$ & 0.15 & 0.06 & $0.42^{\mathrm{a}}$ & 0.43 & 0.17 & 7.924 & $0.004^{* *}$ \\
\hline RFP-palatal & 0.69 & 0.27 & 0.12 & 0.39 & 0.96 & 0.03 & 0.25 & 0.21 & 0.08 & 2.220 & $0.143 \mathrm{NS}$ \\
\hline RFM-tip & 3.59 & 2.61 & 1.65 & 3.52 & 2.62 & 1.03 & 3.51 & 3.54 & 1.45 & 0.230 & $0.797 \mathrm{NS}$ \\
\hline RFM-apex & 0.91 & 2.78 & 0.54 & 0.27 & 3.71 & 1.52 & 0.45 & 3.62 & 1.48 & 0.536 & $0.569 \mathrm{NS}$ \\
\hline RFM-angle & 3.79 & 2.09 & 0.85 & 5.35 & 3.57 & 1.50 & 3.45 & 4.57 & 1.50 & 0.502 & $0.615 \mathrm{NS}$ \\
\hline RFM-buccal & $0.33^{\mathrm{b}}$ & 0.47 & 0.11 & $1.16^{\mathrm{b}}$ & 0.19 & 0.08 & $0.48^{\mathrm{a}}$ & 0.12 & 0.53 & 12.02 & $0.001^{* *}$ \\
\hline RFM-palatal & 2.23 & 0.81 & 0.38 & 3.56 & 0.63 & 0.26 & 1.53 & 0.36 & 0.11 & 0.861 & $0.245 \mathrm{NS}$ \\
\hline LFP-tip & 3.66 & 2.06 & 0.84 & 0.37 & 2.38 & 0.38 & 3.28 & 2.89 & 1.18 & 1.990 & $0.171 \mathrm{NS}$ \\
\hline LFP-apex & 0.37 & 1.42 & 0.57 & 5.93 & 2.42 & 0.99 & 0.58 & 2.28 & 0.93 & 0.501 & $0.616 \mathrm{NS}$ \\
\hline LFP-angle & 5.93 & 3.79 & 1.14 & 5.24 & 3.88 & 1.85 & 5.29 & 2.93 & 1.99 & 2.664 & $0.090 \mathrm{NS}$ \\
\hline LFP-buccal & $0.46^{\mathrm{b}}$ & 0.18 & 0.08 & $0.35^{\mathrm{b}}$ & 0.21 & 0.06 & $0.58^{\mathrm{a}}$ & 0.14 & 0.07 & 16.92 & $0.000^{* * *}$ \\
\hline LFP-palatal & 2.32 & 041 & 0.17 & 3.60 & 0.19 & 0.05 & 0.32 & 0.31 & 0.14 & 0.478 & $0.118 \mathrm{NS}$ \\
\hline LFM-tip & 3.98 & 1.61 & 0.65 & 3.21 & 5.62 & 2.03 & 3.68 & 3.54 & 1.45 & 1.501 & $0.255 \mathrm{NS}$ \\
\hline LFM-apex & 1.26 & 1.78 & 0.54 & 0.68 & 3.71 & 1.52 & 0.53 & 3.62 & 1.48 & 3.266 & $0.066 \mathrm{NS}$ \\
\hline LFM-angle & 4.33 & 1.79 & 0.85 & 5.68 & 3.57 & 1.50 & 4.33 & 4.57 & 1.50 & 0.483 & $0.626 \mathrm{NS}$ \\
\hline LFM-buccal & $0.27^{b}$ & 0.47 & 0.17 & $0.32^{\mathrm{b}}$ & 0.29 & 0.28 & $0.39^{\mathrm{a}}$ & 0.32 & 0.13 & 8.896 & $0.003^{* *}$ \\
\hline LFM-palatal & 1.92 & 0.88 & 0.28 & 0.63 & 0.53 & 0.26 & 1.92 & 0.35 & 0.11 & 0.901 & $0.388 \mathrm{NS}$ \\
\hline
\end{tabular}

$D=$ standard deviation,$\quad S E=$ standard error,$\quad N S=$ Non Significant,$\quad * *=$ highly significant $p \leq 0.005$, $* * *=$ highest significant $p \leq 0.0005$ 
Comparison of the treatment effects between groups which ANOVA has been performed to compare the mean difference among three groups. At revealed only for statistics significance difference in only four variables, so it was followed by Bonferroni post hoc test for this variables. The Bonferroni post hoc test revealed a statistically significance increase in right and left buccal alveolar bone thickness of the molar and premolar area in group III than the other two groups (I\&II) that showed non statistics significance difference between them.

\section{DISCUSSION}

The concept of corticotomy relies on creating bony blocks with embedded teeth that can be moved rapidly with strong forces, the selective decortication in the form of lines is performed between teeth that are to be moved as unite. In addition, a restorable bone graft is placed over the surgical sites to augment the confining bone graft during tooth movement. After a healing period of one or two weeks, orthodontic tooth movement is started and then followed up using faster rate of activation. This technique has several advantages, including faster tooth movement, shorter treatment time, safer expansion of constricted arches, enhanced post-orthodontic treatment stability and extended envelope of tooth movement ${ }^{(12,13)}$.

In the present study it was preferred to use banded hyrex expander in three groups because of its hygienic property and minimal irritation of the palatal mucosa in addition to its controlled expansion without the need of the patient's cooperation. One quarter turns twice daily were applied to obtain expansion of $0.5 \mathrm{~mm}$ per day to ensure minimal tooth movement, the activation period was approximately 20 days for 3 groups.

Concerning the changes in the buccal bone at premolar and molar area, the bone augmentation group (Group III) showed a statistical significance increase in the buccal bone thickness after RME. While the other two groups (I\&II) showed a statistical significance decrease in the buccal bone thickness. These findings support the hypothesis that bone augmentation of the corticotomy reinforced the buccal bone during RME and elimination dehiscence formation. ${ }^{(26,27)}$ these were in agreement with findings of Wilcko et al. ${ }^{(12)}$, Garib et al. ${ }^{(20)}$, Ballanti et al. ${ }^{(21)}$, and others ${ }^{(22,23)}$.

The changes in the palatal bone thickness in the present study have shown a significant increase in first premolar palatal bone thickness (FP- palatal) and first molar palatal bone thickness (FM- palatal) post RME in the three groups. The comparison between the three groups revealed non-statistically significant difference in the palatal dentoalveolar thickness of the posterior teeth between three groups. This finding can be attributed to the buccal tipping of the posterior teeth, which increases the distance between the palatal cortical plate and the root surfaces. This is in agreement with Cotton ${ }^{(24)}$.

\section{CONCLUSIONS}

With the limitation of the present study it could concluded that:

1. Buccal bone graft with buccal surgically assisted RME in young adult does not affect the maxillary basal bone width when compared with the buccal or buccopalatal surgically assisted RME without bone graft.

2. Buccopalatal surgically assisted RME might induce statistical significant increase in maxillary basal bone width.

3. The buccal bone graft with surgically assisted RME in young adult leads to increase in buccal bone thickness than the other technique without bone graft. The other two techniques without bone graft showed significant reduction in buccal bone thickness.

4. Buccal crown tipping concomitant with RME in young adult is not affected by the site of corticotomy either buccal or buccopalatal with or without bone graft. 


\section{REFERENCES}

1. McNamaraa J. Maxillary transverse deficiency. Am J Orthod Dentofacial Orthop. 2000; 117:567-70.

2. Northway W, Meade Jr J. Surgically assisted rapid maxillary expansion: a comparison of technique, response, and stability. Angle Orthod. 1997; 67:309-20.

3. Cureton S, Cuenin M. surgically assisted rapid palatal expansion: orthodontic preparation for clinical success. Am J Orthod Dentofacial Orthop. 1999 31; 116:46-59.

4. Berger J, Pangrazio-Kulbersh V, Borgula T, Kaczynski R. Stability of orthopedic and surgically assisted rapid palatal expansion over time. Am J Orthod Dentofacial Orthop. 1998; 114:638-45.

5. Larsson C, Millqvist E, Bende M. Relationship between subjective nasal stuffiness and nasal patency measured by acoustic rhinometry. Am J rhino. 2001; 15:403-5.

6. Harvold E, Chierici G, Vargervik K. Experiments on the development of dental malocclusions. Am J Orthod. 1972; 61:38-44.

7. Øgaard B, Larsson E, Lindsten R. The effect of sucking habits, cohort, sex, intercanine arch widths, and breast or bottle feeding on posterior crossbite in Norwegian and Swedish 3-year-old children. Am J Orthod Dentofacial Orthop. 1994; 106:161-6.

8. Haas A. The treatment of maxillary deficiency by opening the midpalatal suture. Angle Orthod. 1965; 35:200-17.

9. Bishara S, Staley R. Maxillary expansion: clinical implications. Am J Orthod Dentofacial Orthop. 1987; 91:3-14.

10. Cano J, Bonilla E: Corticotomy-assisted orthodontics. J Clin Exp Dent 2012; 4:54-9.

11. Wilcko W, Wilcko M, Bouquot J, Ferguson D. Accelerated orthodontics with alveolar reshaping. J Orthod Pract 2000; 10:63-70.

12. Wilcko W, Wilcko M, Bouquot J, Ferguson D. Rapid orthodontics with alveolar reshaping: two case reports of decrowding. Int J Perio Restor Dent. 2001; 21:9-20.

13. Wilcko M, Wilcko W, Bissada N. An evidence-based analysis of periodontally accelerated orthodontic and osteogenic techniques: a synthesis of scientific perspectives. Semi Orthod. 2008; 14:305-316.

14. Berger J, Pangrazio-Kulbersh V, Borgula T, Kaczynski R. Stability of orthopedic and surgically assisted rapid palatal expansion over time. Am J Orthod Dentofacial Orthop. 1998; 114:638-45.

15. Swennen G, Schutyser F. Three-dimensional cephalometry: spiral multi-slice vs cone-beam computed tomography. Am J Orthod Dentofacial Orthop. 2006; 130:410-6.

16. Moreira C, Sales M, Lopes P, Cavalcanti M. Assessment of linear and angular measurements on three-dimensional cone-beam computed tomographic images. Oral Surgery, Oral Medicine, Oral Pathology, Oral Radiology, and Endodontology. 2009; 108:430-6.

17. Baysal A, Uysal T, Veli I, Ozer T, Karadede I, Hekimoglu S. Evaluation of alveolar bone loss following rapid maxillary expansion using cone-beam computed tomography. Kor J of Orthod. 2013; 43:83-95.

18. Akyalcin S, Schaefer J, English J, Stephens C, Winkelmann $\mathrm{S}$. Cone-beam computed tomography evaluation of buccal bone thickness following maxillary expansion. Imaging science in dentistry. 2013; 43:85-90.

19. Toklu M, Germec-Cakan D, Tozlu M. Periodontal, dentoalveolar, and skeletal effects of tooth-borne and toothbone-borne expansion appliances. Am J Orthod Dentofacial Orthop.2015; 148:97-109.

20. Garib D, Henriques J, Janson G, de Freitas M, Fernandes A. Periodontal effects of rapid maxillary expansion with tooth-tissue-borne and tooth-borne expanders: a computed tomography evaluation. Am J Orthod Dentofacial Orthop. 2006; 129:749-58.

21. Ballanti F, Lione R, Fanucci E, Franchi L, Baccetti T, Cozza P. Immediate and post-retention effects of rapid maxillary expansion investigated by computed tomography in growing patients. Angle Orthod. 2009; 79:24-9.

22. Yen S, Yamashita D, Kim T, Baek H, Gross J. Closure of an unusually large palatal fistula in a cleft patient by bony transport and corticotomy-assisted expansion. J Oral Maxillofac surg. 2003; 61:46-50.

23. Sebaoun JD, Kantarci A, Turner JW, Carvalho RS, Van Dyke TE, Ferguson DJ. Modeling of trabecular bone and lamina dura following selective alveolar decortication in rats. J Perio. 2008; 79:79-88.

24. Cotton LA. Slow maxillary expansion: skeletal versus dental response to low magnitude force in Macaca mulatta. Am J Orthod. 1978; 73:1-23. 